Anthropological Institute by Wayland and Burkitt (62; 1932). The collections made by Wayland are all in the Museum of Archæology and Ethnology at Cambridge. Now, further investigations have been started under the auspices of the British Institute of History and Archæology in East Africa by Dr. Posnansky and Dr. Glen H. Cole of Chicago. Much interesting material has been unearthed, including some samples of charcoal, which, it is hoped, will give some dates by the carbon-14 method. A preliminary report appears in the July issue of Man. All students interested in the Late Stone Age in Eastern Africa will look forward to further reports which are to appear in due course.

\section{Health Education in the U.S.S.R.}

A ONE-MONTH study visit to the U.S.S.R. was arranged in Juno 1961 for health education specialists from 17 countries by the World Health Organization. The pur. pose was to investigate the role of health education in the U.S.S.R. system of health services. The tour included large urban centres, rural areas, industrial concerns and schools in the Russian Soviet Federative Socialist Republic and the Soviet Socialist Republics of the Ukraine and Uzbekistan. A report outlines the principles of health education as it is practised in the U.S.S.R., describes its planning and organization, research and training aspects, its role in schools, and its implementation through interested agencies such as the Alliance of the Red Cross and Red Crescent Societies, and by means of novol campaigns such as the 'People's Health Universities' (World Health Organization. Public Health Papers, No. 19: Health Education in the U.S.S.R. Pp. 70. Geneva, World Health Organization, 1963. $3 \mathrm{Sw}$. francs; $5 s$. ; 1 dollar). A typical course is outlined in an annex to the report. The health organization programme appears to be characterized by a strong central administration which gives general technical guidance as to goals, organization and methods, and at the same time permits flexibility in adapting approaches to local conditions. The administrative structure of the health education services is described in detail; the two million doctors, nurses, feldshers and midwives, who are in daily contact with the population, play a major part in influencing health knowledge and practices. The present. day public health objectives for which health oducation has an important contribution to make include reduction or eradication of certain communicable diseases, maternal and child health, informing the public on cardiovascular diseases, cancer, accident prevention and the recruitment of volunteer health workers. The particular emphasis laid on preventive as well as curative work, which is so characteristic of the Soviet medical services, is well illustrated in the organization of health education.

\section{Positive Health}

A symposium in a recent issue of The Practitioner (191, 1143; September 1963) has been inspired by one of its readers. More than a year ago a suggestion was received from a general practitioner that the journal should 'publish' a symposium on 'health, rather than diseases'. In days when the cruder forms of disease are gradually coming under control it is incroasingly important that more attention should be paid to those slight aberrations, physical, mental, social or spiritual, that can prevent an individual from living the fullest possible life. The tendency hitherto has been to assume that preventive medicine was the prerogative of the medical officer of health. It is now realized that prevention is just as much part of the work of the family doctor. The introduction of the National Health Service has emphasized this, if only in so far as practitioners are held responsible for the health of the individual from the moment he or she is conceived until the moment of death. In recent years there has been a tendency to emphasize the curative aspects of the practice of medicine, with the rosult that the younger generation of family doctors is not sufficiently strongly imbued with the old philosophy that the family doctor was responsible not only for treating his patients when they are ill, but also for keeping a watchful eye on them and trying to prevent their becoming invalids. The nine articles in the symposium illustrate how much can be done by the general practitioner in helping to maintain the health of the community.

\section{Arterial Hypertension}

Arterial hypertension and ischæmic heart disease carry a high mortality, are increasing in incidence, and kill at the prime of life. The problem is a complex one, since their clinical manifestations vary from country to country; the chief hazard in the United States, for example, is coronary atherosclerosis and in Japan cerebrovascular accidents. The problem is difficult to solve, because what is particularly lacking is an adequate scientific basis for effective prevention. Until there is a 'common language' in the world comparisons between observations made in different places will be impossible to make or be deceptive. The task of establishing the 'common language' is of international importance. Drs. A. Burgess, Z. Fejfar and A. Kagan have made an attempt to provide a common basis of understanding for such terms as validity, precision, accuracy, sensitivity and specificity, repeatability and indices (World Health Organization, Public Health Papers. Arterial Hypertension and Ischaemic Heart Disease: Comparison in Epidemiological Studies. Pp. 36. Geneva, World Health Organization, 1963. $1 \mathrm{Sw}$. franc; $1 s .9 d . ; 0 \cdot 30$ dollars). Before any problem is studied on a world-wide scale, the questions of torminology and methodology discussed in this volume require to be solved. The authors go on to make recommendations on the methods to use, the characteristics to measure, the techniques of measurement, the training of personnel to carry out the measurements, the critical analysis of the data and the recording of results. The report also contains indications of the way in which electrocardiograms and arterial blood pressure should be recorded and interpreted. There are two annexes containing the questionnaires that were used, one on cardiac pain, and the other on tobacco smoking. This volume should be of value to anyone who wishes to apply epidemiological methods to cardiovascular research. It is a relatively new approach, and it is hoped that, by the use of these methods, light will be shed on problems that so far have not been completely solved by clinical observation or anatomical investigation.

\section{Poliomyelitis}

Althodgr the polio immunization campaign has virtually eliminated the disease in Britain, it has, according to an Office of Health Economics Report, been responsible for increasing rather than cutting down the cost of the National Health Service. Because polio affects both children and adults it has been necessary to vaccinate some 25 million people. This involved the largest single immunization programme ever undertaken in Britain. The campaign cost at least $£ 14$ million up to the end of 1961, and its completion involved tho expenditure of approximately another $£ 4$ million. This is greater than the estimated cost of treating the cases of polio which would have occurred if there had been no vaccination. The report comments that "it is important to recognize that the eradication of a disoase may be a very costly process. It is amply repaid by indirect economic savings and social benefits to the community". Poliomyelitis became a serious epidemic in 1947. For the next ten years an average of 4,500 people contracted the disease annually. Vaccination started in 1956, and by 1962 the number of cases of polio had dropped to 271 . In the first half of this year notifications of the disease amounted to only one-fifth of the number in the same period last year. It will cost less to immunize future 